\title{
PHƯƠNG PHÁP BộC Lộ VAN HAI LÁ TRONG PHÃ̃ THUẬT SỦA VAN HAI LÁ NỘI SOI TẠI TRUNG TÂM TIM MẠCH BỆNH VIỆN E
}

Phạm Thành Đạt*, Đoàn Quốc Hung**, Nguyễn Công Hự**, Lê Ngọc Thành*

\section{I. ĐẶT VẤN ĐỀ}

Bộc lộ tốt van hai lá là một trong những yếu tố quyết định thành công sửa van, nhất là trong phẫu thuật tim hở nội soi. Đã có nhiều phương pháp, dụng cụ được phát triển ứng dụng trong phẫu thuật tim hở ít xâm lấn, tuy nhiên việc bộc lộ van hai lá nhiều khi chưa đầy đủ và gặp một số khó khăn nhất định. Trải qua 5 năm áp dụng phương pháp ít xâm lấn, nội soi trong phẫu thuật tim hở, chúng tôi đã cải tiến kĩ thuật bộc lộ van hai lá với những phương tiện đơn giản, đem lại hiệu quả phẫu thuật.

\section{II. ĐỐI TƯợNG VÀ PHƯƠNG PHÁP NGHIÊN CỨU}

\section{1 Đối tượng}

Nghiên cứu được thực hiện tại Trung tâm tim mạch Bệnh viện $\mathrm{E}$ từ tháng 11 năm 2016 đến tháng 4 năm 2019, bao gồm 56 bệnh nhân được chẩn đoán hở van hai lá có chỉ định phẫu thuật sửa van, được áp dụng phẫu thuật tạo hình van hai lá nội soi.

\subsection{Phương pháp}

Các bệnh nhân trong nghiên cứu được áp dụng phẫu thuật nội soi tạo hình van hai lá theo quy trình: (1) tuần hoàn ngoài cơ thể (THNCT) ngoại vi gồm ống động mạch đùi đặt vào động mạch đùi phải qua đoạn mạch nhân tạo số 8 với hai ống tĩnh mạch chủ trên và chủ dưới qua tĩnh mạch đùi phải và tĩnh mạch cảnh trong phải (đặt qua da); (2) đường mở ngực phải $3 \mathrm{~cm}$ vị trí giữa đường nách trước và đường nách giữa (dưới nếp lằn vú ở nữ, khoang liên sườn 5 ở nam), mở ngực vào khoang liên sườn 5; (3) Bảo vệ cơ tim bằng dung dịch Custodiol HTK truyền xuôi dòng qua gốc động mạch chủ và cặp động mạch chủ qua thành ngực.

Van hai lá được tiếp cận qua đường mở nhĩ trái. Kĩ thuật bộc lộ van hai lá bằng các sợi chỉ khâu treo. Năm sợi chỉ Prolene 4/0 được sử dụng. Sợi chỉ thứ nhất và thứ hai khâu treo mép trên đường mở nhĩ trái qua lỗ mở ngực hoặc treo vào thành ngực trước, tránh vị trí bó mạch ngực trong phải. Mũi chỉ thứ 3 khâu mép dưới đường mở nhĩ trái vào màng tim (màng tim được kéo ra ngoài qua lỗ trocart đặt camera nội soi). Mũi chỉ chứ 4 và 5 khâu treo thành trước nhĩ trái ở vị trí $10 \mathrm{~h}$ và $2 \mathrm{~h}$ cách vòng van hai lá $2 \mathrm{~cm}$, các sợi chỉ này được kéo xuyên qua thành ngực hoặc qua trường mổ qua đó nâng vách liên nhĩ, bộc lộ van hai lá. Một số sợi chỉ có thể được sử dụng cho thành sau nhĩ trái, khâu vào vòm hoành phải. Các dụng cụ banh mở ngực, nâng kéo tâm nhĩ sử dụng bản kim loại với cánh tay đòn được loại bỏ hoàn toàn.

* Trung tâm Tim mạch Bệnh viện E

** BV HN Việt Đức, Truò̀ng ĐH Y Hà Nội

Ngưòi chịu trách nhiệm khoa học: PGS.TS.Đoàn Quốc Hung

Ngày nhận bài: 01/07/2019 - Ngày Cho Phép Đăng: 20/07/2019

Phản Biện Khoa học: PGS.TS. Đặng Ngọc Hùng GS.TS. Lê Ngoc Thành 


\section{KẾT QUẢ NGHIÊN CÚU}

Bảng 1: Đặc điểm bệnh nhân

\begin{tabular}{|c|c|}
\hline Tuổi (giá trị trung bình $\pm \mathrm{SD}$ ) & $52.8 \pm 15.6(20-73)$ \\
\hline \multicolumn{2}{|l|}{ Phân loại NYHA } \\
\hline NYHA I & $5(9 \%)$ \\
\hline NYHA II & $32(57 \%)$ \\
\hline NYHA III-IV & $19(24 \%)$ \\
\hline \multicolumn{2}{|l|}{ Các chỉ số trên siêu âm tim } \\
\hline LVEF, giá trị trung bình $\pm \mathrm{SD}(\%)$ & $70.8 \pm 8.6$ \\
\hline Dd & $59.1 \pm 6.3$ \\
\hline Ds & $34.6 \pm 5.1$ \\
\hline Kích thước nhĩ trái & $42.4 \pm 8.1$ \\
\hline Áp lực động mạch phổi trung bình & $35.9 \pm 13.1$ \\
\hline \multicolumn{2}{|l|}{ Mức độ hở van hai lá } \\
\hline Hở van hai lá vừa - nhiều & $4(7 \%)$ \\
\hline Hở van hai lá nhiều & $52(93 \%)$ \\
\hline
\end{tabular}

Bảng 2: Các kĩ thuật tạo hình van hai lá

\begin{tabular}{|l|l|}
\hline Đặt vòng van hai lá & $54(96 \%)$ \\
\hline Cắt tam giác/ tứ giác lá sau & $20(36 \%)$ \\
\hline Khâu gấp nếp lá sau & $25(45 \%)$ \\
\hline Tạo hình dây chằng nhân tạo lá trước & $11(19 \%)$ \\
\hline Mở rộng nhu mô lá trước bằng màng tim & $2(3.6 \%)$ \\
\hline
\end{tabular}

Bảng 3: Đặc điểm trong và sau mổ

\begin{tabular}{|l|l|}
\hline Thờigianchạymáy THNCT, phút & $172 \pm 30$ \\
\hline Thờigiancặp ĐMC, phút & $115 \pm 32$ \\
\hline Thờigianrútống NKQ, giờ & $12.1 \pm 4.6$ \\
\hline Thờigian ICU, giờ & $65.8 \pm 30.6$ \\
\hline Thờigiannằmviện, ngày & $10.6 \pm 4.8$ \\
\hline
\end{tabular}


Bảng 4: Kết quả, biến chứng

\begin{tabular}{|c|c|c|}
\hline \multicolumn{2}{|c|}{ Chuyển mở xương ức } & $1(1.8 \%)$ \\
\hline \multicolumn{2}{|c|}{ Mở rộng đường mở ngực } & $1(1.8 \%)$ \\
\hline \multicolumn{2}{|c|}{ Thay van } & $6(11 \%)$ \\
\hline \multirow{4}{*}{ Mổ lại } & Chảy máu & $2(3.6 \%)$ \\
\hline & Máu cục màng phổi & $1(1.8 \%)$ \\
\hline & Thay van & 0 \\
\hline & Khác & 0 \\
\hline \multicolumn{2}{|c|}{ Tai biến mạch não } & $1(1.8 \%)$ \\
\hline \multicolumn{2}{|c|}{ Lóc tách động mạch chủ } & 0 \\
\hline \multicolumn{2}{|c|}{ Tổn thương phổi phải cấp sau mổ } & $2(3.6 \%)$ \\
\hline \multicolumn{2}{|c|}{ Phù phổi cấp sau mố } & $1(1.8 \%)$ \\
\hline \multicolumn{2}{|c|}{ Tử vong } & $1(1.8 \%)$ \\
\hline
\end{tabular}

Bảng 5: Siêu âm tim sau mổ

\begin{tabular}{|c|c|c|c|c|}
\hline \multicolumn{2}{|l|}{ Chỉ số } & Trước mổ & Sau mổ & $\mathrm{P}$ \\
\hline \multicolumn{2}{|l|}{ Nhĩ trái (mm) } & $42.4 \pm 8.1$ & $36.3 \pm 5.8$ & 0.0064 \\
\hline \multicolumn{2}{|l|}{$\operatorname{Dd}(\mathrm{mm})$} & $59.1 \pm 6.3$ & $48.6 \pm 5.1$ & $<0.0001$ \\
\hline \multicolumn{2}{|l|}{$\operatorname{Ds}(\mathrm{mm})$} & $34.6 \pm 5.1$ & $31.7 \pm 4.3$ & 0.0478 \\
\hline \multicolumn{2}{|l|}{$\mathrm{EF}(\%)$} & $70.8 \pm 8.6$ & $61.1 \pm 6.1$ & 0.0001 \\
\hline \multicolumn{2}{|c|}{ Áp lực ĐMP (mmHg) } & $35.9 \pm 13.1$ & $23.8 \pm 4.1$ & 0.0002 \\
\hline \multirow{5}{*}{ Hở van hai lá } & No or trace & 0 & $36(64 \%)$ & \\
\hline & Nhẹ(1+) & 0 & $18(32 \%)$ & \\
\hline & Vừa(2+) & & $2(4 \%)$ & \\
\hline & Vừa đến Nặng & $4(7 \%)$ & 0 & \\
\hline & Nặng(4+) & $52(93 \%)$ & 0 & \\
\hline
\end{tabular}




\section{BÀN LUẬN}

Phẫu thuật sửa van hai lá nội soi, nội soi hỗ trợ đã được tiến hành tại nhiều trung tâm phẫu thuật tim trên thế giới, và có những bước tiến mạnh mẽ đặc biệt với sự hỗ trợ của robot. Tại Trung tâm tim mạch bệnh viện $\mathrm{E}$ phẫu thuật van hai lá ít xâm lấn nội soi hỗ trợ đã được triển khai từ 2013, cho tới nay thay van hai lá với phương pháp này đã trở thành thường quy. Đối với sửa van hai lá, chúng tôi thực hiện từ nửa đầu 2015, khi các thao tác với phẫu trường mới bắt đầu trở nên thuần thục. Trong giai đoạn này, chúng tôi chủ động lựa chọn bệnh nhân với những tổn thương đơn giản như đơn thuần lá sau - với các kĩ thuật tạo hình van hai lá không quá phức tạp. Theo kinh nghiệm của chúng tôi, một trong những khó khăn nhất của phẫu thuật là sự bộc lộ hoàn chỉnh van hai lá trong toàn bộ cuộc mổ, điều đó dẫn tới những thử thách nhất định trong quá trình sửa van bao gồm đặt vòng van hai lá (nhất là vòng van kín), sửa chữa các lá van, đo van, kiểm tra hoạt động của van. Trong thực hành lâm sang có nhiều bộ dụng cụ khác nhau được sử dụng để kéo nâng tâm nhĩ bộc lộ van. Cấu hình kỹ thuật hầu hết sử dụng một cánh tay đòn xuyên qua thành ngực, sau đó gắn với một má kim loại mỏng áp sát vào vách lien nhĩ kéo vách lien nhĩ ra trước, cánh tay đòn được cố định vào khung banh ngực [5]. Các bộ dụng cụ này thường có giá thành cao nhưng vẫn tồn tại nhược điểm thường phải tạo một lỗ 4-5mm qua thành ngực (nguy cơ chảy máu sau mổ). Trong nhiều tình huống lâm sang chọn vị trí tối ưu để đặt dụng cụ này gặp khó khăn, vướng vào phẫu trường. Trải qua nhiều cải tiến, từ quý 3 năm 2016, chúng tôi bắt đầu áp dụng kĩ thuật bộc lộ van hai lá bằng các sợi chỉ khâu treo kéo nâng thành tâm nhĩ không phải mở them lỗ qua thành ngực do đó hạn chế nguy cơ chảy máu sau mổ, dễ dàng chọn và thay đổi vị trí cho phù hợp mà không gây sang chấn, phương tiện đơn giản (không cần bộ dụng cụ phức tạp, giá thành cao), thao tác dễ dàng và tiết kiệm thời gian phẫu thuật, đặc biệt đạt mục đích bộc lộ bộ máy van hai lá tốt nhất, phẫu trường mổ rõ rang không bị vướng bởi dụng cụ. Hơn nữa với những trường hợp nhĩ trái nhỏ, trường mổ sâu, có thể đặt thêm các mũi chỉ treo ở các "góc chết", qua đóviệcbộclộ van hai lá được thực hiện một cách linh hoạt. Kĩ thuật đã được áp dụng cho tất cả 55 bệnh nhân (trừ một trường hợp phải mổ mở - do toàn bộ phổi phải dính vào thành ngực), đều được bộc lộ van hai lá tốt mà không cần thêm bất kì dụng cụ hỗ trợ nào.

Trong số 56 bệnh nhân, có một trường hợp phải mở rộng đường mở ngực từ $3 \mathrm{~cm}$ lên $5 \mathrm{~cm}$, nguyên nhân do không đặt được tĩnh mạch cảnh trong phải qua da, phải mở rộng vết mổ để đặt thêm một ống tĩnh mạch trực tiếp vào tĩnh mạch chủ trên. Tuy nhiên các thao tác khâu treo nhĩ trái với kĩ thuật của chúng tôi trong trường hợp này vẫn hoàn toàn thuận lợi và đạt được mục tiêu bộc lộ van hai lá.

Trong 3 bệnh nhân chảy máu phải mổ lại, một trường hợp chảy máu từ bục đường khâu gốc động mạch chủ. Bệnh nhân đột ngột chảy máu ngày thứ 2 tại phòng hồi sức sau khi đã rút ống NKQ, phẫu thuật lại thay đoạn động mạch chủ lên, bệnh nhân tử vong sau mổ 18 tiếng vì suy tim, cung lượng tim thấp. Đây là trường hợp tử vong duy nhất trong nghiên cứu: bệnh nhân 73 tuổi tiền sử đặt stent LAD 2 tháng trước phẫu thuật, ĐTĐ type II phụ thuộc Insulin, động mạch 
chủ lên $40 \mathrm{~mm}$ và thành động mạch chủ mỏng. Mặc dù chúng tôi đã khá thận trọng với trường hợp gốc động mạch chủ này trong mổ tuy nhiên biến chứng vẫn xảy ra, điều này để lại một số kinh nghiệm trong lựa chọn đối tượng của phẫu thuật: với các bệnh nhân tuổi cao, có nhiều yếu tố nguy cơ cần cân nhắc kĩ lưỡng việc có áp dụng phương pháp nội soi ít xâm lấn hay không. Trường hợp chảy máu còn lại từ chân dẫn lưu thành ngực. Một trường hợp làm sạch máu cục khoang màng phổi nguyên nhân chảy máu thành ngực trước ở vị trí sợi chỉ khâu treo.

Đặc biệt, trong 56 bệnh nhân nghiên cứu có một trường hợp phù phổi cấp sau mổ. Bệnh nhân nam 64 tuổi, cao $170 \mathrm{~cm}$, nặng $73 \mathrm{~kg}$. Quá trình phẫu thuật phải gỡ dính phổi phải, gỡ dính gốc động mạch chủ, cặp động mạch chủ gặpkhó khăn, tim đập lại nhiều lần trong mổ, tổng cộng truyền 9lít dung dịch custodiol. Sau mổ xuất hiện phù phổi cấp 2 bên, quá trình hồi sức hút ống NKQ rất nhiều dịch vàng trong. Sau một tuần, hai phổi dần hồi phục . Bệnh nhân ra viện sau 3 tuần điều trị. Hai trường hợp khác chúng tôi gặp biến chứng tổn thương phổi phải cấp sau mổ đều liên quan tới thời gian chạy tim phổi máy kéo dài, một trường hợp phải đặt ECMO hỗ trợ 8 ngày, cả hai bệnh nhân đều hồi phục và ra viện sau 1 tháng điều trị. Đây là những biến chứng rất nặng nề, tỷ lệ tử vong lên đến $30 \%$ theo một số nghiên cứu []. Cả 3 trường hợp này đều gặp tổn thương phức tạp (hở van hai lá do Osler) thất bại trong việc sửa van phải thay van, thời gian mổ kéo dài. Tuy nhiên cả 3 bệnh nhân đều ra viện mà không để lại di chứng, đặc biệt với phương pháp bộc lộ van hai lá của chúng tôi việc thay hay sửa van đều có thể thực hiện được với các thao tác thuận lợi, an toàn.

\section{KẾT LUẬN}

Phẫu thuật sửa van hai lá nội soi tại trung tâm tim mạch bệnh viện $\mathrm{E}$, với những cải tiến kỹ thuật trong bộc lộ van hai lá: dễ thực hiện, đạt được mục đích bộc lộ van hai lá với những phương tiện đơn giản, giảm chi phí cuộc mổ. Kết quả ngay sau phẫu thuật và theo dõi sau một tháng hiệu quả, an toàn. 